\title{
A Study on Problems of Chinese-English Translation of Public Signs in Dazhou Based on the PRC National Standard*
}

\author{
SU Yan-fei \\ Sichuan University of Arts and Science, Sichuan, China
}

\begin{abstract}
Besides having a multitude of functions including prompting, directing, referring, and publicizing and the like, public sign shoulders the responsibility of building city image as well as reflecting a local government's capability of public service and governance, playing a critical role in improving city image, and strengthening soft power. Based on the People's Republic of China National Standard: Guidelines for the Use of English in Public Service Areas, this paper studies the status quo of Chinese-English translation of public signs in downtown areas of Dazhou, a medium-sized city in eastern Sichuan, China, finding a variety of problems, such as understanding, grammar, wording, word-for-word translation, spelling, and so forth; meanwhile, this paper provides suggestions about translation of public signs and revised translation for reference in order to improve translation quality.
\end{abstract}

Keywords: Dazhou, public signs, Chinese-English translation, the PRC National Standard: Guidelines for the Use of English in Public Service Areas

\section{Introduction}

With the deepening of China's Reform and Opening-up and the increasing popularity of the Belt and Road Initiative, China has being appreciating improvement in terms of its international influence, image, and status. Local governments at various levels in China actively respond to the central government's appeal to vigorously introduce oneself to foreign countries and strive for an early achievement of promoting one's integration into the world. Consequently, numerous cities across China have embarked on translating their public signs into English, which is one of the most important ways to reflect its internationalization. The Chinese-English translation of public signs has become a significant part in promoting publicity of a city to foreigners, which also reflects a city's civilization and openness (Lv, 2005). It, on the other hand, is directly connected with building and improving city image as well as reflecting a city's capability of public service and governance.

The governments at all levels and the academia in China, therefore, have attached importance to translation of public signs. For instance, governments of various levels have funded research projects in this regard. Furthermore, some introduced their own local standard of guidelines for the Chinese-English translation of signs in public service areas one after another, including the first experts committee for Chinese-English translation of names in public areas in 2014, which was guided by the Shanghai Municipal Government, followed by Guangzhou and Beijing. Finally, the People's Republic of China National Standard: Guidelines

\footnotetext{
${ }^{*}$ Acknowledgements: This paper is supported by Sichuan University of Arts and Science (Grant No.: 2018BWH001Y), the Education Research and Reform Project of SASU (Grant No.:2017JY15) and the Research Center of Southwest Minority (Grant No.:XNYJY1803).

Su Yan-fei, M.A., lecturer, School of Foreign Languages, Sichuan University of Arts and Science, Sichuan, China.
} 
for the Use of English in Public Service Areas (GB/T 30240.1-2013 and GB/T 30240.2-2017) (hereinafter referred to as the PRC National Standard) was introduced and implemented in 2014 and 2017, respectively. On the other hand, the academia in China have vigorously conducted studies, with research papers being published soaring. For example, roughly 742 papers revolving around translation of public signs in years from 2003 to 2017 were retrieved by searching CNKI (China National Knowledge Infrastructure) with key words in the paper title of "public signs translation", while Li (2014) found 592 papers in this regard in years from 2003 to 2012. Within five years, there was an increase of 150 papers about public signs translation. Generally speaking, both the governments and the academia in China have paid critical attention to Chinese-English translation of public signs.

\section{The Status Quo of Translation of Public Signs in China}

Researchers have carried out various studies of translation of public signs from numerous perspectives. For a start, there were studies focusing on those in provincial capitals and special administrative regions in China, for example, public signs in Guizhou (Wang \& Xie, 2013), Hongkong Special Administrative Region (Lin, 2015), Chengdu (Kang, 2017), Chenzhou (Tan, 2014), and so on. Secondly, there were studies mainly giving attention to specific type of public signs, such as those on university campus in China (Hou, 2016) and names of streets (Jing, 2014).

Although a number of studies on public signs translation in China were conducted, there are still various translation problems or mistakes at present. According to Luo, Xu, and Shu's (2014) research, the densest distribution of problems related to public signs translation in scenic spots took place in Sichuan, a southeastern province in China, compared with those in another seven provinces or autonomous regions in western China. Studies taking Chinese-English translation of public signs in Dazhou's downtown areas as an object, at present, are scarce, with few focusing on those in Dazhou's tourist destinations. Moreover, there is still no local standard of guidelines for the Chinese-English translation of signs in public service areas. At the same time, according to the field research on Chinese-English translation of public signs in downtown areas of Dazhou, an eastern city of Sichuan, translation problems are present in large numbers, which deserve attentions and solutions from the local government and the academia.

Under the guidance of the PRC National Standard, this paper conducts research on Chinese-English translation of public signs in downtown areas of Dazhou, analyzing, classifying, and summarizing the translation problems. It also proposes suggestions for dealing with those problems and provides corresponding revised translation for reference so as to standardize Dazhou's public signs translation, improving its translation quality so that it is beneficial to improve its international image and strengthens its soft power and on the other hand to supply certain reference materials for its neighboring cities. Meanwhile, this paper also wants to communicate with other scholars across the world about the translation of public signs and gain suggestions from English native speakers.

\section{Current Chinese-English Translation Problems in Downtown Areas of Dazhou}

The definition of public sign in this paper was cited from Lv (2005), namely, "Showing to the public, public sign means words or characters or signs which notice, direct, prompt, show, caution and help people to identify information related to their livelihood, production, lives, environment and profession (p. 22)”. 
Under the guidance of Lv's definition of public sign, the Chinese-English translation of public signs is characterized by being accurate, concise, normal, consistent, appropriate, eye-catching, popular, and easy-to-understand and the like so that various functions of public signs could be realized.

A field research into Chinese-English translation of public signs in downtown areas of Dazhou was carried out in 2017, in which relevant public signs were photographed. Then, after sorting out and classifying these photos, photos which represented a type of public areas, such as street, shopping mall, and railway station were selected. There were 221 photos, among which 75 ones were chosen. The valid English words and Chinese characters in those 75 photos were transcribed into text information. In the end, 154 items of public signs were transcribed into 1,090 Chinese characters and 730 English words.

The current transcribed text was analyzed and plenty of problems were found, including word for word translation, scraping different versions together and copying other's translation indiscriminately, and so on. In general, the translation quality is not looking good. The translation problems could be roughly divided into two types, namely, translation errors and language faults (see Figure 1). Taking the fact that some translations have more than one problem into consideration, the number of problems was counted one by one. Due to space limitation, problems would not be cited one after another. Instead, major ones were given specific explanation after all problems were analyzed and classified, followed by revised translation for reference, which was formed under the guidance of the PRC National Standard.

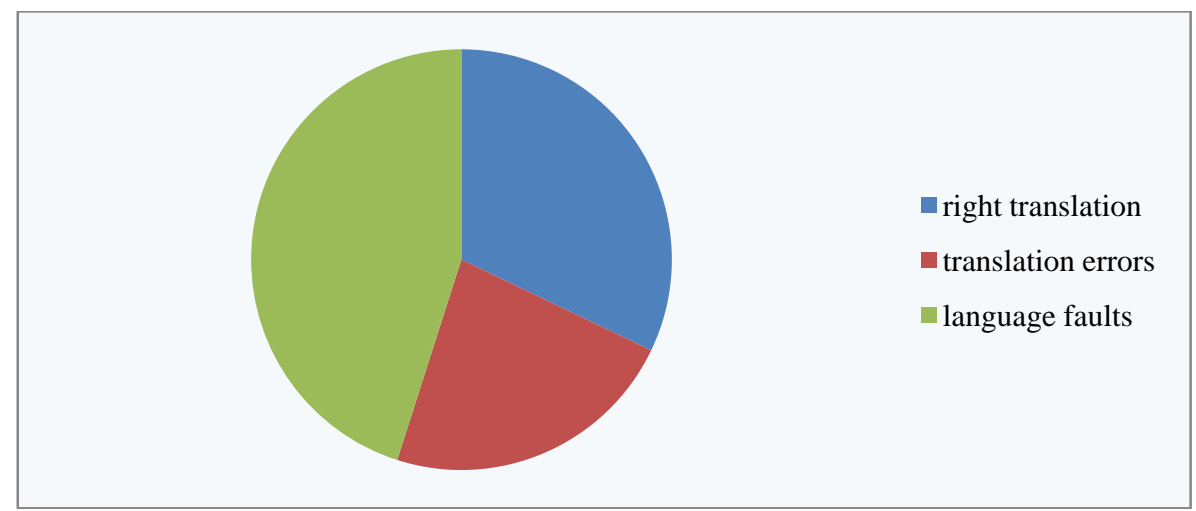

Figure 1. Chinese-English translation of public signs in downtown areas of Dazhou.

\section{Translation Errors}

According to the analysis of the transcripts of Chinese-English translation of public signs in Dazhou, a multitude of translation errors were found, which could be generally classified into four types including misunderstandings of the source text, grammar mistakes, misnomers, and word for word translations (see Figure 2). Specific explanations are given as follows. 


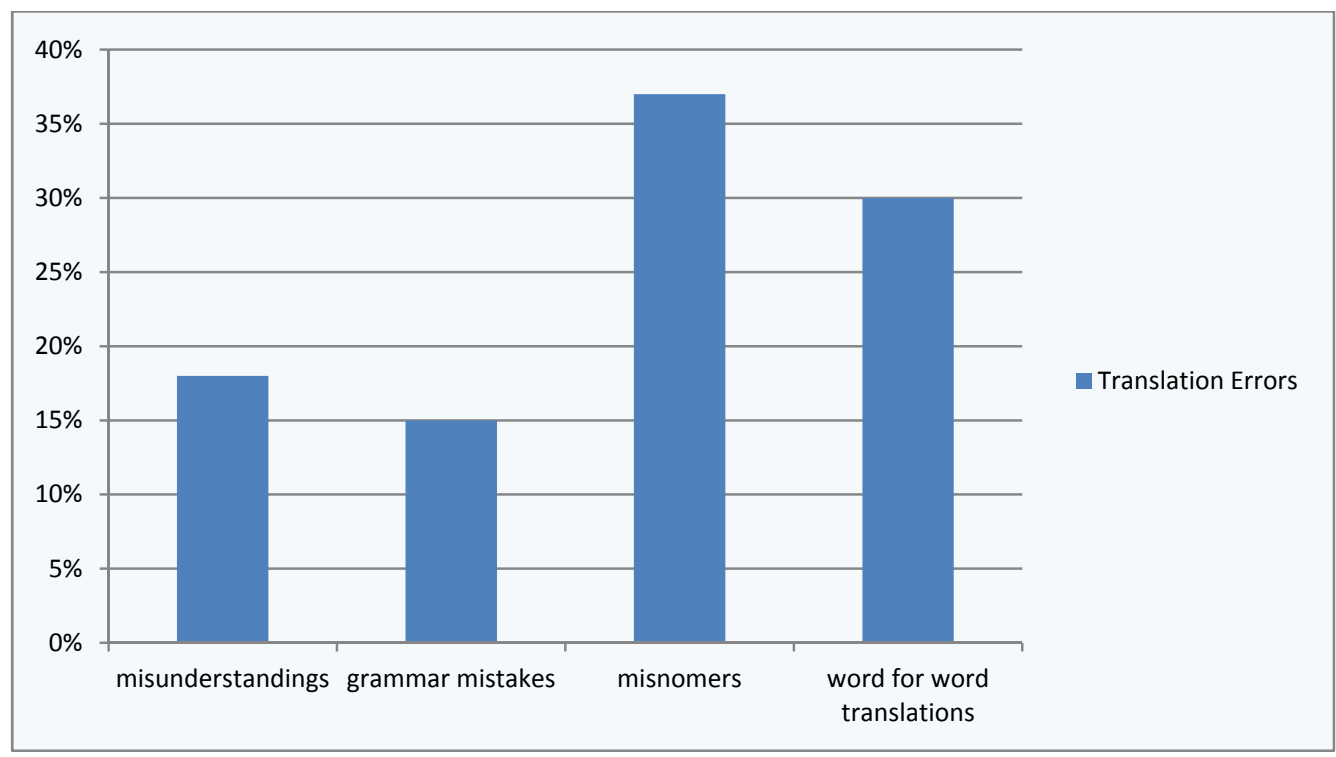

Figure 2. Translation errors.

Misunderstandings. Misunderstanding in this paper means that meaning of the original text is misunderstood so that it is not reproduced in the target text. Such problems take place occasionally.

Next to an escalator in a shopping mall is a public sign, “请勿依靠” was translated into “Please Do Not Trust In" which had several errors. To begin with, in light of its Chinese characters, there is misunderstanding which leads to misnomer. In Chinese, “依靠” and “倚靠” have substantial difference, with the former referring to a person or a thing which could be relied on or trusted in and the latter having the meaning of one leaning against an object. Therefore, the original meaning is leaning against the escalator. Secondly, because of the misunderstanding and misnomer of the original Chinese text, the original translation is wrong. Consequently, consulting the PRC National Standard which regulates that public sign item belonging to prohibition which has the function of dissuading people from doing something could be translated into "Please Do Not..." or "Thank You for Not-ing”, this paper revises it into "Please Do Not Leaning” or "Thank You for Not Leaning". Moreover, both versions could be used but a consistency should be assured.

In China, fire fighting facilities are required to be installed in some public areas and corresponding public signs must be set. There is no exception in Dazhou. As for translation of such public signs in Dazhou, there are still many errors. For example, the source text of “消防栓” was translated into “FIRE HOSE REEL”. “消防栓” means a water pipe in a street from which firefighters can obtain water for putting out fires burning. Therefore, “消防栓” should be translated into “Fire Hydrant”.

The public sign, “餐饮服务食品安全等级公示” was translated into “Food amd Drug Administration”, which has spelling error and misunderstanding of the original text. The "amd" is spelled wrongly, which should be "and". Then, the original translation refers to an organization which supervises the safety of food and drug, but the source text means a notice showing safety level of food, hence the revised version is "Food Safety Grades Notification”.

Grammar mistakes. Grammar mistake in this paper refers to those in English translation which do not abide by English grammar rules. Comparatively speaking, such mistakes in Chinese-English translation of public signs in Dazhou are minimal. 
“禁止带入宠物” was translated into “Pet Are Not Allowed”, which did not follow the rule of agreement of subject and predicate. Here, "pet" should be "pets" or "are" is changed to "is". A public sign next to an escalator, “老、幼、病、残、及不适者乘梯时, 需有人陪同” was translated into “Elderly, young, sick, disabled, and physically ill will take the escalator, Need someone accompany". There is misnomer and word for word translation as well as tense problem. It should use present tense instead of future tense. Therefore, it could be revised to "The elderly, children, patients, and the disabled should be escorted while taking the escalator".

Misnomers. Misnomer in this paper means describing something in wrong or unsuitable expression. Such problem is usually due to different ways of thinking or language usage between Chinese and English. Taking the translation of public sign of “达州市食品药品监督管理局” as an example, it was translated into “Dazhou County Food and Drug Administration”, among which “市” should be translated into “city” instead of “county” (县). They are different levels of administrative divisions. For the PRC National Standard, some administrative division in certain context can be omitted, so here it could be translated into "Dazhou Food and Drug Administration”. Next, “禁止在商场内吸烟” was translated into “please do not smoke”, which did not reproduce the original tone. According to the PRC National Standard, public sign item involved with prohibition could be translated into "Do Not...”, "No-ing”, or “...Not Allowed”, the revised version, hence, could be "Do not smoke", "No Smoking", or "Smoking is not allowed". Any version could be chosen on the condition that it is in consistency.

Word for word translations. Word for word translation in this paper means rendering of source text in one language to target text in another language focuses on word level, which does not convey the original meaning. Readers will not understand it.

“严禁抛物” was translated into “No parabolic”. Typing the Chinese characters, “严禁抛物” into Youdao, an online dictionary, "No parabolic" turns up. It is obvious that the word parabolic is wrongly used. Referring to the PRC National Standard, it is revised into "Throwing Prohibited".

The above-mentioned public sign, “老、幼、病、残、及不适者乘梯时, 需有人陪同” was translated word by word as "Elderly, young, sick, disabled, and physically ill will take the escalator, Need someone accompany". The revised version could be "The elderly, children, patients, and the disabled should be escorted while taking the escalator".

\section{Language Faults}

Another serious problem in the Chinese-English translation of public signs in the downtown areas of Dazhou is language fault, which refers to those problems that English versions do not meet the English language's expression habit. Mistakes could be divided into plenty of types. This paper mainly discusses four types including misspelling, irregular spelling, mixture of capital and small letters, and inconsistency of words (see Figure 3). 


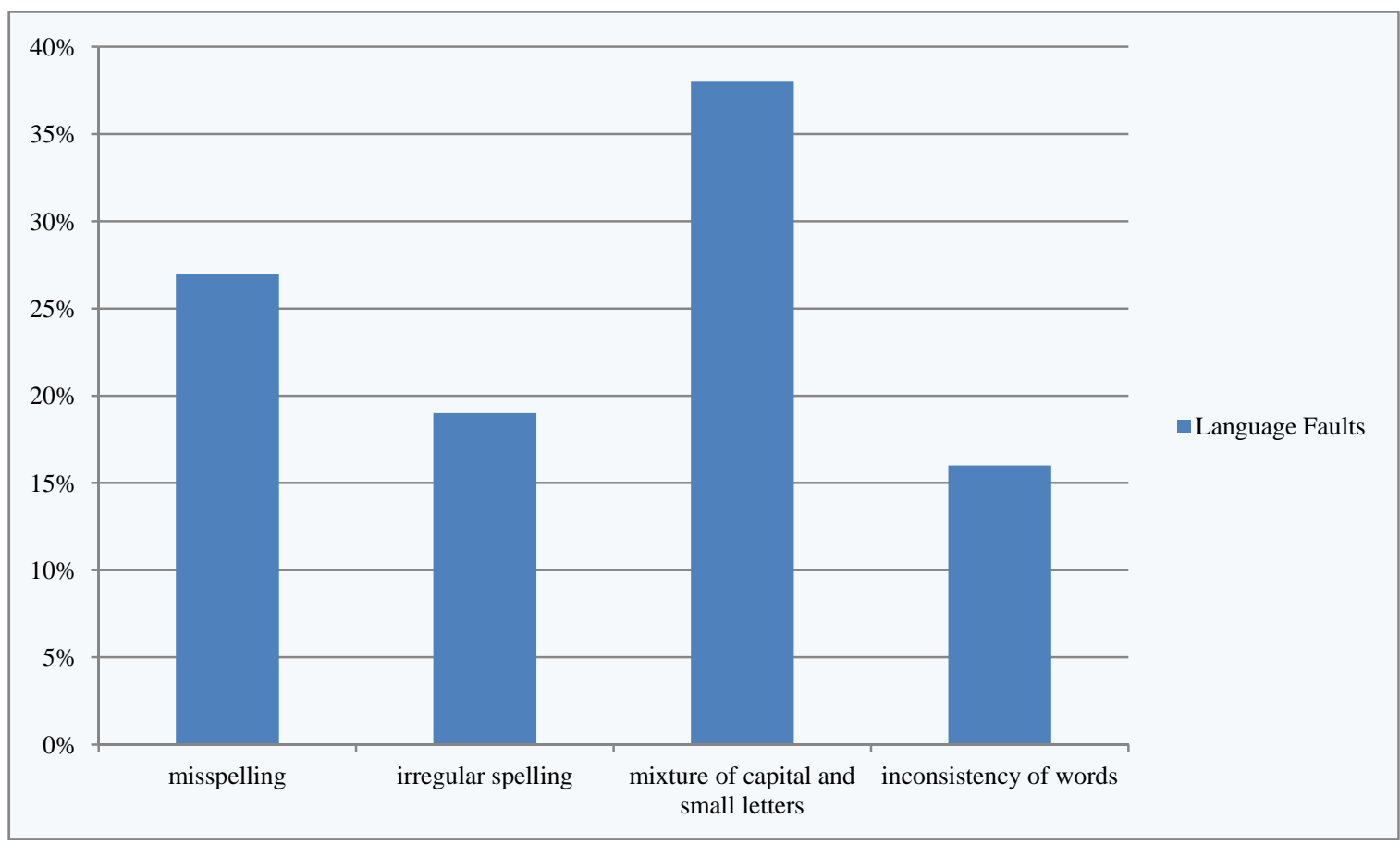

Figure 3. Language faults.

Misspelling. Misspelling in this paper refers to word which is spelt wrongly. Misspelling of Chinese-English translation of public signs in Dazhou reflects that translators or people who were responsible for the translation had poor sense of responsibility and weak translation capabilities. For instance, the public sign, “楼层索引” was translated into "DIRECTIORY”, in which the seventh letter "I" should be left out. Furthermore, the public sign of “取走办理的全部产品” was translated into “Take All Youy Products”, in which the word "Youy” was spelt wrongly and the right one is “your”. Then, the public sign, “小心地滑” was translated into "Caut Wet Floor", in which the word "caut" was a misspelling and the right one is "caution". At the same time, there is a misnomer. According to the PRC National Standard, a public sign having the function of a general caution could be translated into "Mind...", "Watch...", or "Beware of...", hence the revised version is "Beware of Wet Floor".

Irregular spelling. It in this paper means spelling of a word is not in accordance with the normal English spelling rules. For example, name of an avenue, “金龙大道” was translated into “JINLONGDA DAO”, in which “金龙” is the name of the avenue and “大道” means a general name used in names of streets in a town or city, so it is an irregular spelling. Consulting the PRC National Standard, it regulates that proper nouns of places and organizations are generally spelt according to their Chinese phonetic alphabet (pinyin) and general names are translated into English. Therefore, the revised version is "Jinlong Avenue”. Some scholars suggested that pinyin should be adopted while translating names of places because a foreigner asks the local for a help of showing directions and the majority of the local could only understand Chinese pinyin, a foreigner could pronounce it and the local understand it and show the direction. Consequently, the revised translation could be “Jin Long Da Dao".

Mixture of capital and small letters. It in this paper refers to spelling of a word does not conform to English spelling rules of capital and small letters. For example, a street, “荷叶街” was translated as “He ye St.”, in which the word "ye" did not conform to the spelling rules and of course it was an irregular spelling. 
Moreover, a public sign, “当心挤伤” was translated into "Beware Of Crushing”, in which the word "Of” should use small letter. And last, a public sign of “对公业务、便民服务、其他业务” was translated as "Corporate Service、 Convenient Service And Others", in which a variety of mistakes exist including translation problems and language faults. The word "And" here should be small letter. There is punctuation problem, that is, “、” should be changed into "comma” (,) because in English, there is no “、”, a slight-pause mark used to set off items in a series or used between parallel words or short phrases and as for serving the same function of the mark, a comma is used in English.

Inconsistency of words. It in this paper refers to the use of proper nouns in same context and having same meaning keeps changing so that the target reader would become confused. For instance, the public sign, “不可 回收”, on the rubbish bin was translated into "UNRECYCLABLE”, “ORGANISM”, and "OTHER WASTE” respectively on rubbish bins, among which the second translation is wrong. It is obvious that the above three translation versions are not consistent. The right translation of the public sign is "Non-Recyclables". Moreover, the name of a place, “凤凰山” was sometimes translated into "Fenghuang Mountain”, while other time into "Phoenix Mountain". The same place has different English names, which would make foreigners confused. Another example is a translation of a place, “莲花湖” which was translated into “Lianhua Lake” and “Lotus Lake". Such translation would make target reader think that there are two different places. The main target readers of the Chinese-English translation of public signs in Dazhou are those who speak or grasp English. At the same time, the translation has function of education. Chinese people can learn English by reading English public signs under the general background that English learning gains popularity among Chinese people. Referring to the suggestions about translation of names of place given by Jing (2014), namely, adopting both Chinese pinyin and English translation on the condition that the two versions are listed in separate lines, this paper revises the former translations into "Fenghuang Shan//Phoenix Mountain" (here the mark "/ /" means the two versions are listed in separate lines.) and "Lianhua $\mathrm{Hu} /$ /Lotus Lake", which is of a great help for target readers to understand the meaning and find their destinations by asking the locals to show them the direction.

It is obvious that the above-mentioned classification of problems of Chinese-English translation of public signs in the downtown areas of Dazhou is the result of being convenient for the paper to make further explanation for each type of problems. In fact, there is no possibility of making a clear-cut classification since a majority of those translations have several translation problems at the same time. Besides major problems, there are minor problems, such as wrong usage of punctuation. There are similarities and differences between Chinese punctuation and English punctuation, but some translators did not pay attention to those differences.

It is well-recognized that public signs should fulfill a valuable social function of educating people besides performing functions of directing, prompting, prohibiting, dissuading, and ordering, to name a few. Under the background that English learning is growingly popular in China, the English public signs could help people learn English, no matter young or old. Furthermore, the Chinese-English translation of public signs is beneficial for students who major in English language because the Chinese-English translation of public signs is another form of bilingual teaching material. Consequently, research on Chinese-English translation of public signs is of great significance and of a great help to standardize translation, minimizing translation errors, and language faults. It as well enjoys important scientific meaning and practical values in improving translation quality.

The Chinese-English translation of public signs in a city is a name card of a city and a window for a city to introduce itself to foreigners, which would exert influence on the first impression of target readers home and abroad as well as have direct relation in building its international image. Lin Kenan (2015) provided three 
suggestions targeting at the Chinese-English translation of public signs, namely, firstly, to carefully select or employ talented translators or excellent translators to translate public signs so as to guarantee a high translation quality; secondly and importantly, to conduct careful proofreading; and last but not the least, to seek for opinions from readers.

Taking the three suggestions into account, this paper proposes that the local government should take lead in organizing translators to translate public signs by referring to measures taken by Shanghai, Beijing, Guangzhou, and other metropolises, such as to establish a specialized translation committee; and then, the government could build a platform for the public to give their opinions on the translation of public signs including a social media, like Wechat and Weibo in order to help improve the translation of public signs; thirdly, the local university should play a role in it and certain majors of a university could avail themselves of the translation material, which could be used as materials for translation students to translate so that they can apply translation techniques or theories into real life translation; and finally, translators should consult native English speakers while translating public signs.

\section{Conclusion}

Under the guidance of the People's Republic of China National Standard: Guidelines for the Use of English in Public Service Areas (GB/T 30240.1-2013 and GB/T 30240.2-2017), this paper makes an in-depth research into the status quo of Chinese-English translation of public signs in downtown areas of Dazhou, carefully analyzing the gathered and transcribed Chinese-English translation materials of public signs, classifying and summarizing current problems, which could be generally divided into two types, that is, translation errors (misunderstandings of the source text, grammar mistakes, misnomers, and word for word translations) and language faults (misspelling, irregular spelling, mixture of capital and small letters, and inconsistency of words). Finally, the paper provides corresponding revised version for reference. It is natural that this paper has certain shortcomings such as research object, Chinese-English translation of public signs in Dazhou, had comparatively small sample size, which could be improved by later adding more samples. Next, it is possible that other problems could be discovered if more samples are added, which deserve further research. It is meaningful that a corpus for Chinese-English translation of public signs in Dazhou will be built.

\section{References}

Dai, Z. X., \& Lv, H. F. (2005). On C-E translation of public signs. Chinese Translators Journal, 26(6), 38-42.

Jing, S. R. (2014). On the transcription of Chinese street names: A case study of Taiyuan city. Journal of North University of China (Social Science Edition), 30(6), 42-45.

Ma, C. M., \& Zhu, Y. P. (2013). A design and development of the Chinese-English parallel corpus of public signs for Shaanxi tourist attractions. Journal of Xi'an International Studies University, 21(1), 113-116.

Luo, J. S., Xu, J., \& Shu, J. (2014). A research on Chinese-English translation of public signs in tourist attractions in western China. Journal of South-Central University for Nationalities (Humanities and Social Sciences), 34(3), 166-171.

Li, L. (2014). What can a translator do? Chinese-English translation of scenic spot signs from the perspective of the functional approach. Chinese Science \& Technology Translators Journal, 27(3), 41-44.

Lin, K. N. (2015). English translation of public signs in Hong Kong: Observation and thinking. Chinese Translators Journal, (5), 101-103.

Hou, Y. F. (2016). A study on Chinese-English translation of public signs on university campus. Chinese Science \& Technology Translators Journal, 29(2), 27-29.

Kang, N. (2017). A study on mistranslation of public signs in Chengdu. Overseas English, (16), 108-109. 
Tan, J. (2014). On the translation of tourism signs in Chenzhou. Journal of Central South University of Forestry \& Technology (Social Sciences), 8(2), 41-43.

Lv, H. F. (2005). On functional features and Chinese-English translation of the expressions on public signs. Terminology Standardization and Information Technology, (2), 21-26/35.

Wang, L. Y., \& Xie, G. H. (2013). On the feasibility of norms of public signs in Guizhou Province. Journal of Kaili University, 31(1), 91-94. 